\title{
Infrared thermographic assessment of changes in skin temperature during hypoglycaemia in patients with type 1 diabetes
}

\author{
Anne-Sophie Sejling ${ }^{1,2}$ • Kai H. W. Lange ${ }^{3}$ - Christian S. Frandsen ${ }^{4}$ - Sarah S. Diemar ${ }^{5}$. \\ Lise Tarnow $^{6,7,8}$ • Jens Faber ${ }^{5,9}$ • Jens J. Holst ${ }^{10}$ • Bolette Hartmann ${ }^{10}$ • Linda Hilsted ${ }^{11}$. \\ Troels W. Kjaer ${ }^{12}$ • Claus B. Juhl ${ }^{2,13}$ • Birger Thorsteinsson ${ }^{1,5}$ • \\ Ulrik Pedersen-Bjergaard ${ }^{1,5}$
}

Received: 27 December 2014 / Accepted: 7 April 2015 /Published online: 19 May 2015

(C) Springer-Verlag Berlin Heidelberg 2015

\begin{abstract}
Aims/hypothesis Hypoglycaemia is associated with reduced skin temperature (Ts). We studied whether infrared thermography can detect Ts changes during hypoglycaemia in patients with type 1 diabetes and how the Ts response differs between patients with normal hypoglycaemia awareness and hypoglycaemia unawareness.

Methods Twenty-four patients with type 1 diabetes (ten aware, 14 unaware) were studied during normoglycaemia (5.0-6.0 mmol/1), hypoglycaemia $(2.0-2.5 \mathrm{mmol} / \mathrm{l})$ and during recovery from hypoglycaemia $(5.0-6.0 \mathrm{mmol} / \mathrm{l})$ using hyperinsulinaemic glucose clamping. During each $1 \mathrm{~h}$ phase, Ts was measured twice by infrared thermography imaging in pre-defined areas (nose, glabella and the five left fingertips),
\end{abstract}

Electronic supplementary material The online version of this article (doi:10.1007/s00125-015-3616-6) contains peer-reviewed but unedited supplementary material, which is available to authorised users.

Anne-Sophie Sejling

sej1@regionh.dk

1 Department of Cardiology, Nephrology and Endocrinology, Nordsjællands Hospital, Dyrehavevej 29, 3400 Hillerød, Denmark

2 Faculty of Health Sciences, University of Southern Denmark, Odense, Denmark

3 Department of Anaesthesiology, Nordsjællands Hospital, Hillerød, Denmark

4 Department of Endocrinology, Hvidovre Hospital, Hvidovre, Denmark

5 Faculty of Health and Medical Sciences, University of Copenhagen, Copenhagen, Denmark symptoms of hypoglycaemia were scored and blood was sampled.

Results Ts decreased during hypoglycaemia on the nose and glabella. The highest decrements were recorded on the nose (aware: $-2.6^{\circ} \mathrm{C}$, unaware: $-1.1^{\circ} \mathrm{C}$ ). In aware patients, the differences in temperature were statistically significant on both nose and glabella, whereas there was only a trend in the unaware group. There was a significant difference in hypoglycaemia-induced temperature changes between the groups. Patients in the aware group had higher hypoglycaemia symptom scores and higher adrenaline (epinephrine) levels during hypoglycaemia.

Conclusions/interpretation The hypoglycaemia-associated decrement in Ts can be assessed by infrared thermography

6 The Research Unit, Nordsjællands Hospital, Hillerød, Denmark

7 Steno Diabetes Center, Gentofte, Denmark

8 Health, Aarhus University, Aarhus, Denmark

9 Department of Endocrinology, Herlev Hospital, Herlev, Denmark

10 NNF Center for Basic Metabolic Research, University of Copenhagen, Copenhagen, Denmark

11 Department Clinical Biochemistry, Rigshospitalet, Copenhagen, Denmark

12 Department of Neurology, Roskilde Hospital, Roskilde, Denmark

3 Department of Endocrinology, Sydvestjysk Sygehus, Esbjerg, Denmark 
and is larger in patients with normal hypoglycaemia awareness compared with unaware patients.

Keywords Adrenalin · Awareness · Counterregulatory response $\cdot$ Diabetes type $1 \cdot$ Hypoglycaemia $\cdot$ Infrared thermography $\cdot$ Symptoms of hypoglycemia $\cdot$ Temperature

$\begin{array}{ll}\text { Abbreviations } \\ \text { ARO } & \text { Specific area of interest } \\ \text { CGM } & \text { Continuous subcutaneous glucose monitor } \\ \text { PP } & \text { Pancreatic polypeptide } \\ \text { Ts } & \text { Skin temperature }\end{array}$

\section{Introduction}

In non-diabetic individuals, hypoglycaemia is associated with a decrease in skin temperature (Ts), which is thought to be mediated by peripheral vasoconstriction and evaporation of sweat $[1,2]$. Cutaneous blood flow is reduced by sympathetic nervous activity and circulating catecholamines. Sweating is mainly mediated by cholinergic fibres, although circulating catecholamines also have an effect [3-5].

While the reduction in temperature during hypoglycaemia is well-described in non-diabetic individuals [2,6], only sparse evidence of this effect has been described in patients with diabetes [7,8]. Absence of Ts reduction during hypoglycaemia in diabetes patients could be due to abnormal neural and hormonal counterregulatory responses. Thus, patients with diabetes may, in response to repetitive exposure to hypoglycaemia, develop hypoglycaemia-associated autonomic failure that in turn may lead to impairment of hypoglycaemia awareness (unawareness) [9]. Patients with impaired hypoglycaemia awareness lack autonomic warning symptoms of hypoglycaemia such as sweating or tremor [10]. Therefore, hypoglycaemia unawareness could influence the thermal response during hypoglycaemia as a direct effect of the blunted sympathetic neural response. Nevertheless, an older study based on the use of temperature sensors on the forehead and abdomen did not reveal any differences in Ts in response to hypoglycaemia between patients with normal and impaired hypoglycaemia awareness [11].

Since then, infrared thermography has emerged as a sensitive measure of Ts without the need for any direct skin contact [12]. The aim of this study was to investigate if infrared thermography can identify changes in Ts during hypoglycaemia in patients with type 1 diabetes and to assess whether any differences exist in the Ts response between hypoglycaemia-aware and unaware patients.

\section{Methods}

The study was a part of a clinical controlled study aimed at investigating the response to hypoglycaemia in patients with type 1 diabetes and either normal hypoglycaemia awareness or unawareness [13]. The protocol was registered at ClinicalTrials.gov (no. NCT01337362) and approved by the Regional Committee on Biomedical Research Ethics. Written informed consent was obtained from all participants.

Participants Twenty-four patients with type 1 diabetes were recruited from the diabetes outpatient clinics at Nordsjællands Hospital and Steno Diabetes Center, Denmark. Inclusion criteria were type 1 diabetes $>5$ years, age $>18$ years and being either hypoglycaemia-aware or unaware. Exclusion criteria included pregnancy or breastfeeding, any brain disorder, use of antiepileptic drugs, beta blocking agents or neuroleptic agents, use of benzodiazepines within the last month, cardiovascular disease and alcohol or drug abuse. Hypoglycaemia awareness status was classified by the Pedersen-Bjergaard method [14], the Gold score [15] and the Clark method [16]. Patients not being either hypoglycaemia-aware or unaware were ineligible. Fourteen patients were hypoglycaemiaunaware and ten patients were hypoglycaemia-aware according to all three methods (electronic supplementary material [ESM] Table 1).

At baseline, information regarding late-stage diabetic complications and neuropathy was obtained by patient interview and review of medical records. Glycaemic control was assessed by measurement of $\mathrm{HbA}_{1 \mathrm{c}}$.

Experimental protocol All experiments were carried out in the same room and efforts were made to secure a stable room temperature throughout the experiment. The participants wore similar clothing and were studied during a glucose clamp at three glucose levels; normoglycaemia, hypoglycaemia and during recovery from hypoglycaemia. At each glycaemic level, which lasted for approximately $1 \mathrm{~h}$ (Fig. 1) identical testing was carried out, including infrared thermographic imaging, blood sampling for measurements of counterregulatory hormonal responses and recording of hypoglycaemia symptom scores.

Continuous subcutaneous glucose monitoring The participants wore a continuous subcutaneous glucose monitor (CGM; Guardian REAL-Time with Enlite sensor, Medtronics, Minneapolis, MN, USA) for 5 days before the glucose clamp. If any glucose measurement was below $3.5 \mathrm{mmol} / \mathrm{l}$ within $24 \mathrm{~h}$ before the experimental day, further study procedures were postponed.

Glucose clamp procedure The glucose targets were 5.0 $6.0 \mathrm{mmol} / \mathrm{l}$ during normoglycaemia, $2.0-2.5 \mathrm{mmol} / \mathrm{l}$ during 


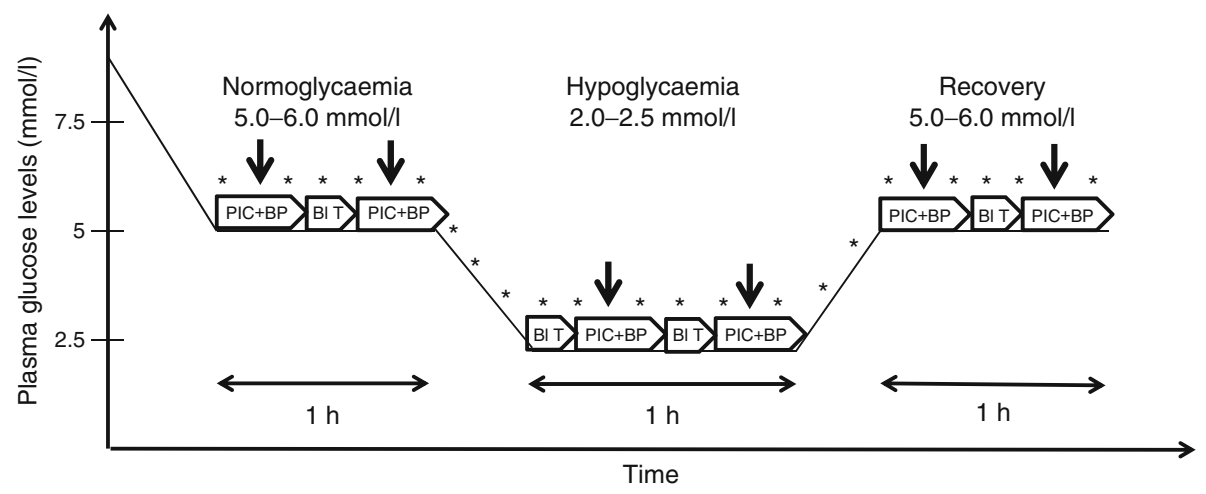

Fig. 1 Study design. A hyperinsulinaemic glucose clamp was performed. When the plasma glucose level reached $5.0-6.0 \mathrm{mmol} / \mathrm{l}$ the scheduled experiment was initiated. The participant was examined during normoglycaemia, hypoglycaemia and recovery following hypoglycaemia. PIC $+\mathrm{BP}$, infrared thermographic images of the face

hypoglycaemia and 5.0-6.0 $\mathrm{mmol} / 1$ during recovery. Insulin was infused intravenously at a continuous rate of $1 \mathrm{mU}$ insulin $\mathrm{kg}^{-1} \min ^{-1}$ (Actrapid, Novo Nordisk, Ballerup, Denmark) while $20 \%$ glucose was infused at a variable rate to keep blood glucose within target. The initial glucose infusion rate during normoglycaemia was similar in all patients $\left(0.015 \mathrm{mmol} \mathrm{kg}^{-1} \mathrm{~min}^{-1}\right)$ and thereafter adjusted on an individual level throughout the clamp. Plasma glucose was measured by YSI 2300 (YSI/XYLEM, Yellow Springs, OH, USA). At the end of each glycaemic period and at the beginning of the hypoglycaemic period, blood was drawn and later analysed for glucagon, adrenaline (epinephrine), noradrenaline (norepinephrine), cortisol and growth hormone levels as previously described [13]. Pancreatic polypeptide (PP) levels were determined by extracting PP from plasma samples with ethanol (70\% [vol./vol.] final concentration) and then measuring it with the use of a mid-region specific antibody (No. HYB 347-07; Statens Serum Institut, Copenhagen, Denmark). Human PP was used as standard and ${ }^{125}$ I-labelled PP (No. NEX315; Perkin Elmer, Boston, MA, USA) was used as a tracer.

Infrared thermographic imaging Information regarding Ts was obtained by an infrared thermographic camera (Thermovision SC645, FLIR Systems, Wilsonville, OR, USA). The recordings provided two dimensional thermal images where each pixel represents a temperature. The thermal camera had an accuracy $\pm 2 \%$, a thermal resolution of $<0.07^{\circ} \mathrm{C}$ and an image resolution of $640 \times 480$ pixels. The images were recorded at the beginning and at the end of each glycaemic phase (Fig. 1). During thermographic recordings, the participants were asked to look directly into the camera and raise their hands so that the palms faced towards the camera. The participant's arms were resting in a fixed plaster cast during the recordings so that position of the hands was the same throughout the study. The camera was fixed in a standardised position in front of the patient, $1.5 \mathrm{~m}$ away. and hands were recorded (PIC), BP was measured and hypoglycaemia symptom scores were recorded. B1 T, blood tests for analyses of counterregulatory hormones. Vertical arrows show the time point for the recording of the thermal images.* indicates plasma glucose measurement

Specific areas of interest (AROs) were selected, including the tip of the nose, the glabella and the tip of all fingers on the left hand (Fig. 2). These areas were chosen so that the same anatomical locations were analysed throughout the study without interfering with the rest of the study set-up. The mean Ts for each ARO were subsequently calculated (ThermaCAM Researcher Professional, version 2.10, FLIR Systems). $\Delta$ Ts is

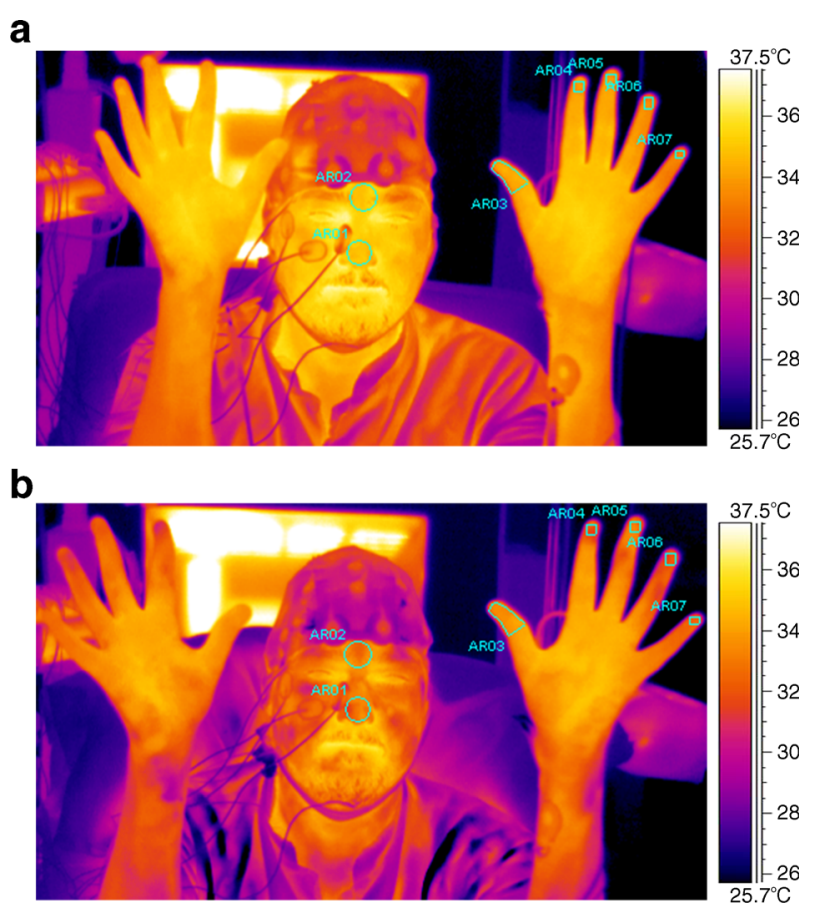

Fig. 2 Examples of thermographic images recorded during normoglycaemia (a) and hypoglycaemia (b) in a hypoglycaemia-aware participant with palms facing towards the camera. The temperature scale was the same for both pictures as can be seen on the vertical scale on the right. Higher temperatures are shown in orange and yellow colours whereas lower temperatures are purple and blue colours. The seven areas of interest (AROs) are marked as ARO1-7 
defined as Ts at the end of the hypoglycaemic level minus the Ts at the beginning of the normoglycaemic level.

Hypoglycaemia symptom scores Patients filled in a standardised hypoglycaemia symptom questionnaire (the Danish modification of the Edinburgh Hypoglycaemia Scale $[17,18])$ twice during normoglycaemia, hypoglycaemia and recovery. The symptoms were grouped into three symptom categories; autonomic, neuroglycopenic and other hypoglycaemia symptoms.

Statistical analysis Data were analysed using the statistical software (IBM SPSS Statistics, version 20, IBM Cooperation, Armonk, NY, USA) and R 2.15.1 (R Foundation for Statistical Computing, Vienna, Austria). Data are expressed as means (SEM) unless otherwise stated. Within-group effects of hypoglycaemia during the hypoglycaemic phase and during the recovery phase were assessed by repeated measures ANOVA, where the assumption of sphericity was made (assessed by Mauchly's test). If the assumption of sphericity was violated, a multivariate ANOVA was performed and significance for Wilks' Lambda reported or Wilcoxon signed rank test was performed as appropriate. The between-group effects were assessed by unpaired $t$ test, a Mann-Whitney test or by a linear mixed model depending on data distribution, occurrence of repeated measurements and homogeneity of intercorrelations. A $p$ value $<0.05$ (two-sided) was considered statistically significant.

\section{Results}

Baseline characteristics of the participants are shown in Table 1. Hypoglycaemia-unaware patients tended to be older, they had a longer duration of diabetes, required a lower daily insulin dose, had lower BMI and had experienced more episodes of severe hypoglycaemia during their lifetime.

Glucose clamp There was no difference in mean glucose levels during normoglycaemia or recovery between the two groups: normoglycaemia aware: $5.4(0.1) \mathrm{mmol} / \mathrm{l}$, mean (SEM) (CV 6.2\%); normoglycaemia unaware: $5.3(0.09)$
Table 1 Baseline characteristics of the 24 participants

\begin{tabular}{llll}
\hline Baseline characteristic & Aware $(n=10)$ & Unaware $(n=14)$ & $p^{\mathrm{a}}$ \\
\hline Men $(n)$ & $7(70 \%)$ & $7(50 \%)$ & 0.4 \\
Age (years) & $45(26-66)$ & $60(40-69)$ & 0.06 \\
Duration of diabetes (years) & $20(8-41)$ & $33(15-54)$ & 0.03 \\
C-peptide $(n)$ & & & 0.4 \\
$<0.02 \mathrm{nmol} / 1$ & $9(90 \%)$ & $12(86 \%)$ & 0.4 \\
$0.02-0.04$ nmol/1 & $1(10 \%)$ & $2(14 \%)$ & 0.4 \\
$\mathrm{HbA}_{1 \mathrm{c}}(\%)$ & $8.1(6.6-9.9)$ & $8.0(6.0-9.5)$ & 0.6 \\
$\mathrm{HbA}_{1 \mathrm{c}}(\mathrm{mmol} / \mathrm{mol})$ & $65(49-85)$ & $64(42-80)$ & 0.6 \\
24 h insulin dose $(\mathrm{U})$ & $51(29-92)$ & $41(11-50)$ & 0.007 \\
$\left.\mathrm{BMI}^{2} \mathrm{~kg} / \mathrm{m}^{2}\right)$ & $27.0(23.9-31.9)$ & $23.5(18.0-27.4)$ & 0.003 \\
Beat-to-beat variation on the ECG & $11(2.6-26)$ & 1 \\
Presence of hypertension $(n)$ & $16(3.2-35)$ & $8(57 \%)$ & 0.7 \\
Presence of nephropathy $(n)$ & $7(70 \%)$ & $1(7 \%)$ & 0.6 \\
Presence of proliferative retinopathy $(n)$ & $2(20 \%)$ & $1(7 \%)$ & 1 \\
Presence of peripheral neuropathy $(n)$ & $1(10 \%)$ & $4(29 \%)$ & 0.7 \\
Presence of autonomic neuropathy $(n)$ & $2(20 \%)$ & $2(14 \%)$ & 1 \\
Episodes with severe hypoglycaemia $($ lifetime) $(n)$ & $2(20 \%)$ & & $<0.001$ \\
0 & $5(50 \%)$ & - & \\
$1-5$ & $4(40 \%)$ & $2(14 \%)$ & \\
$6-10$ & $1(10 \%)$ & $9(64 \%)$ & \\
$11-20$ & - & & \\
$\geq 21$ & - & & \\
\hline
\end{tabular}

Data are median (range) or $n(\%)$

${ }^{a}$ Differences between the groups for continuous variables were assessed by a $t$ test and the categorical variables were assessed by Fisher's exact test

${ }^{\mathrm{b}}$ Beat-to-beat variation was the mean of five measurements assessing the difference between maximal and minimal pulse frequency during five respiration cycles where the patient was asked to take a deep quick breath, hold for 5 seconds and then exhale fast and wait for 5 seconds 
$\mathrm{mmol} / \mathrm{l}(\mathrm{CV}$ 6.7\%), $p=1$; recovery aware: $5.6(0.09) \mathrm{mmol} / 1$ (CV 6.5\%); recovery unaware: $5.6(0.1) \mathrm{mmol} / 1$ (CV 5.1\%), $p=0.7$ (Fig. 3). During hypoglycaemia, the mean plasma glucose was $2.5(0.05) \mathrm{mmol} / 1$ (CV 3.8\%) with a nadir of $2.3(0.06) \mathrm{mmol} / \mathrm{l}$ in the aware group and $2.3(0.02) \mathrm{mmol} / \mathrm{l}$ (CV 6.3\%) with a nadir of $2.0(0.04) \mathrm{mmol} / \mathrm{l}$ in the unaware group $\left(p_{\text {hypo }}=0.04\right.$ and $\left.p_{\text {nadir }}<0.001\right)$. This was despite a lower glucose infusion rate during hypoglycaemia in the aware group (aware: $0.011 \mathrm{mmol} \mathrm{kg} \mathrm{min}^{-1}$, unaware $\left.0.017 \mathrm{mmol} \mathrm{kg}^{-1} \mathrm{~min}^{-1}, p=0.02\right)$.

Thermography The mean Ts during normoglycaemia in the aware group was $34.0(0.8)^{\circ} \mathrm{C}$ on the nose and $35.2(0.2)^{\circ} \mathrm{C}$ on the glabella. In the unaware group it was $33.2(0.8)^{\circ} \mathrm{C}$ on the nose and $35(0.1)^{\circ} \mathrm{C}$ on the glabella. There were no statistically significant differences between the two groups at normoglycaemia.

During hypoglycaemia, Ts on the nose and glabella decreased in the aware group (nose: $\Delta \mathrm{Ts}-2.6^{\circ} \mathrm{C}, 95 \% \mathrm{CI}$ $[-3.8,-1.5], p=0.005$; glabella: $\Delta \mathrm{Ts}-1.4^{\circ} \mathrm{C}, 95 \% \mathrm{CI}[-2.1$, $-0.8], p=0.02 ;$ Fig. 4$)$. In the unaware group, there was only a trend towards a lower temperature on both nose $\left(\Delta \mathrm{Ts}-1.1^{\circ} \mathrm{C}\right.$, $95 \% \mathrm{CI}[-2.4,0.1], p=0.07)$ and glabella $\left(\Delta \mathrm{Ts}-0.4^{\circ} \mathrm{C}, 95 \%\right.$ CI $[-0.9,0.05], p=0.07)$. The differences in the hypoglycaemia-associated temperature changes between the
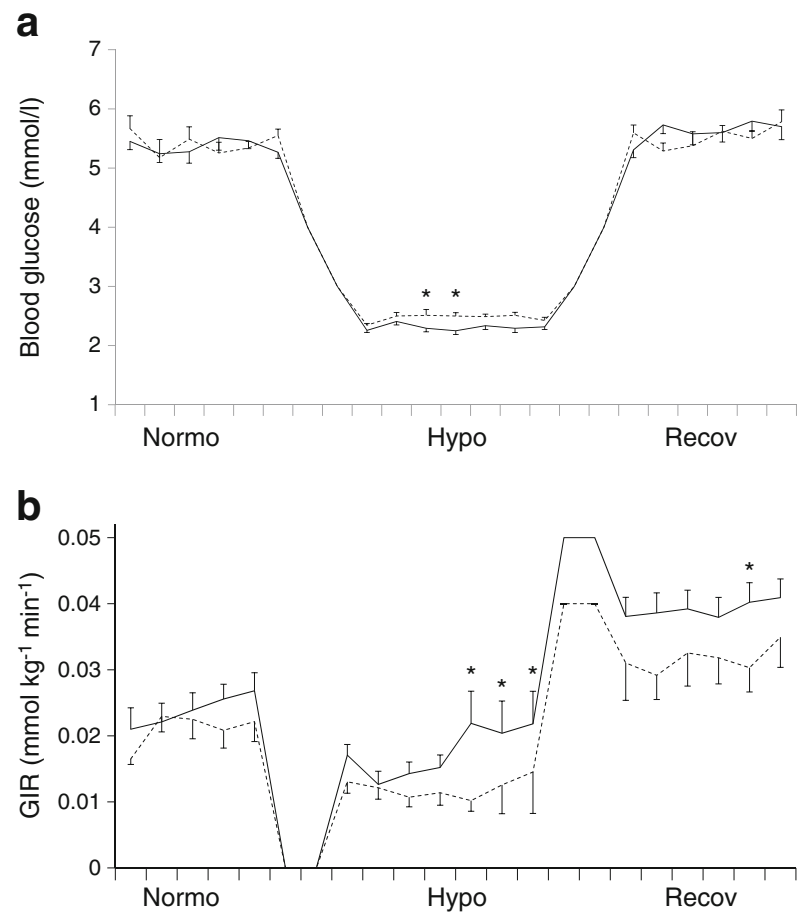

Fig. 3 Mean plasma glucose levels (a) and glucose infusion rates (GIR) (b) in the two groups during the three periods of the study: Normo (normoglycaemia), Hypo (hypoglycaemia) and Recov (recovery). Dashed lines, aware group; black lines, unaware group. Error bars depict SEM. ${ }^{*} p<0.05$, difference in glucose levels between the two groups as assessed by Mann-Whitney tests
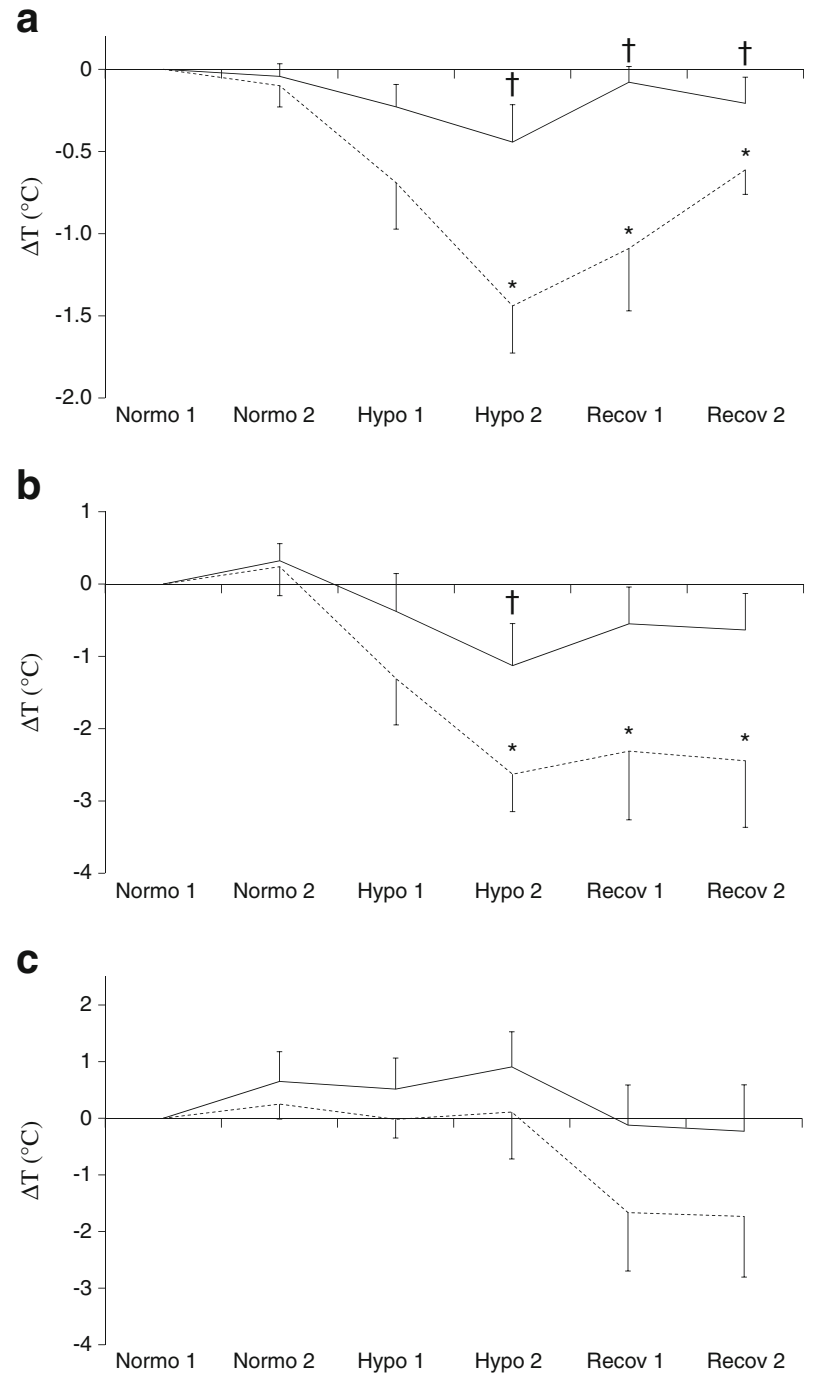

Fig. 4 Ts changes $(\Delta \mathrm{T})$ on glabella (a), nose (b) and first finger (c) (see ESM Fig. 1 for other fingers). Dashed lines, hypoglycaemia-aware patients; black lines, hypoglycaemia-unaware patients. Normo (normoglycaemia), Hypo (hypoglycaemia) and Recov (recovery), showing the first and second measurements (1 and 2; see Fig. 1). Error bars depict SEM. ${ }^{*} p<0.05$ when compared with normoglycaemia; ${ }^{\dagger} p<0.05$ aware vs unaware

two groups were significant for both nose $(p=0.04)$ and glabella $(p=0.02)$.

There were no changes in Ts on any finger during hypoglycaemia compared with normoglycaemia in any of the groups but Ts decreased during recovery in the aware group (Table 2, ESM Fig. 1).

The linear mixed model also showed a significant reduction in Ts on the glabella and nose during both hypoglycaemia and recovery: nose: $\Delta \mathrm{Ts}-2.6(0.6)^{\circ} \mathrm{C}(\mathrm{SEM}), p<0.001$; glabella $\Delta \mathrm{Ts}-1.4(0.3)^{\circ} \mathrm{C} ; p<0.001$. After adjusting for awareness, $\mathrm{BMI}$, age and duration of diabetes, the Ts changes on the glabella and nose were still significant. On the glabella, changes in Ts were associated with awareness status ( $p=0.002)$ but 
independent of BMI, age and duration of diabetes. On the nose, Ts changes also differed between the two awareness groups during recovery $(p=0.02)$, while there was a trend towards a difference during hypoglycaemia $(p=0.07)$. This was also independent of BMI, age and duration of diabetes.

Room temperature was stable throughout the experimental days with a temperature of $24.2 \pm 0.2^{\circ} \mathrm{C}($ mean \pm SEM) with no significant difference between periods of normoglycaemia and hypoglycaemia or between study groups.

BP and pulse There was no difference in systolic BP between the different glycaemic levels or between the two groups. Diastolic BP decreased during hypoglycaemia but only in the aware group: from 78 (2) $\mathrm{mmHg}$ to 73 (2) $\mathrm{mmHg}, p=$ 0.005 . As a consequence, the pulse pressure increased during hypoglycaemia in the aware group: normoglycaemia: 57 (3) $\mathrm{mmHg}$ (mean); hypoglycaemia 70 (5) $\mathrm{mmHg}$ (max), $p=0.01$. $\Delta$ hypo (the maximal level during hypoglycaemia minus the level during normoglycaemia) for pulse increased in both groups (aware: $\Delta$ hypo 5.5 beats-per-min [bmp], $p=0.005$; unaware: $\Delta$ hypo $7.8 \mathrm{bpm}, p=0.002$ ), with no difference between the two groups (ESM Table 2).

Counterregulatory hormonal responses There was an increase in plasma concentrations of all measured hormones during hypoglycaemia in both groups (ESM Table 2). When comparing the response in the aware and unaware groups, $\Delta$ hypo for adrenaline and cortisol were higher in the aware group (adrenaline: $\Delta$ hypo aware $0.68[0.16] \mathrm{ng} / \mathrm{ml}$, unaware $0.35[0.08] \mathrm{ng} / \mathrm{ml}, p=0.048$; cortisol: $\Delta$ hypo aware 295 [59] $\mathrm{nmol} / \mathrm{l}$, unaware $134[35] \mathrm{ng} / \mathrm{ml}, p=0.02$ ). There were no significant differences in $\Delta$ hypo for glucagon, noradrenaline, growth hormone and PP between the two groups. During recovery, noradrenaline remained increased in the aware group $(0.67[0.1] \mathrm{ng} / \mathrm{ml})$, but not in the unaware group $(0.45[0.05]$ $\mathrm{ng} / \mathrm{ml} ; p=0.04)$. The unaware group had higher PP levels at baseline (aware 6.5 [1.1]pmol/1; unaware 16.9 [3.1]pmol/1; $p=0.006$ ).

Hypoglycaemia symptom scores The aware group reported increased symptom scores in all three categories during hypoglycaemia (autonomic symptoms: $\Delta$ hypo 8.6 [2.0] points, $p=0.008$; neuroglycopenic symptoms: $\Delta$ hypo 14.6 [4.5] points, $p=0.02$; other symptoms: $\Delta$ hypo 5.4 [2.0] points, $p=0.007)$ (ESM Table 3). In the unaware group there were increases in autonomic and neuroglycopenic scores during hypoglycaemia (autonomic symptoms: $\Delta$ hypo 2 [1.1] points, $p=0.02$; neuroglycopenic symptoms: $\Delta$ hypo 4.8 [1.9] points, $p=0.047$ ) whereas there was only a trend towards an increase in other symptom scores ( $\Delta$ hypo $0.6[0.3]$ points, $p=0.06$ ). The aware group scored higher in all three categories compared with the unaware group (all $p<0.05$ ).
Table 2 Ts on nose, glabella and finger tips on the palmar side of the left hand during normoglycaemia, hypoglycaemia and recovery ${ }^{\mathrm{a}}$

\begin{tabular}{|c|c|c|c|c|c|c|c|}
\hline Variable & $\begin{array}{l}\text { Normo } \\
\text { start }\end{array}$ & $\begin{array}{l}\text { Normo } \\
\text { end }\end{array}$ & $\begin{array}{l}\text { Нуро } \\
\text { start }\end{array}$ & $\begin{array}{l}\text { Нypo } \\
\text { end }\end{array}$ & $\begin{array}{l}\text { Recovery } \\
\text { start }\end{array}$ & $\begin{array}{l}\text { Recovery } \\
\text { end }\end{array}$ & $p^{\mathrm{b}}$ \\
\hline \multicolumn{8}{|l|}{ Aware } \\
\hline F1 & $32.5(0.8)$ & $32.7(0.8)$ & $32.5(0.8)$ & $32.6(0.7)$ & $30.7(1.2)$ & $30.8(1.1)$ & 0.04 \\
\hline $\mathrm{F} 2$ & $32.1(0.8)$ & $32.4(0.8)$ & $31.8(0.9)$ & $32.0(0.9)$ & $30.1(1.2)$ & $30.1(1.2)$ & 0.04 \\
\hline F3 & $31.8(0.8)$ & $32.3(0.8)$ & $31.5(0.9)$ & $31.8(0.9)$ & $30.1(1.2)$ & $29.9(1.1)$ & 0.08 \\
\hline F4 & $31.6(0.8)$ & $32.1(0.7)$ & $31.5(0.9)$ & $31.7(0.9)$ & $29.6(1.3)$ & $29.7(1.1)$ & 0.07 \\
\hline F5 & $31.4(0.8)$ & $32.0(0.7)$ & $31.6(1.0)$ & $31.5(1.0)$ & $29.5(1.3)$ & $29.5(1.0)$ & 0.050 \\
\hline Nose & $33.8(0.9)$ & $34.0(0.7)$ & $32.5(0.9)$ & $31.2(0.9)$ & $31.4(1.0)$ & $31.3(1.2)$ & 0.009 \\
\hline Glabella & $35.3(0.3)$ & $35.2(0.2)$ & $34.6(0.4)$ & $33.9(0.4)$ & $34.2(0.5)$ & $34.7(0.4)$ & $<0.001$ \\
\hline \multicolumn{8}{|l|}{ Unaware } \\
\hline F1 & $31.7(0.8)$ & $32.4(0.8)$ & $32.2(0.7)$ & $32.6(0.4)$ & $31.6(0.7)$ & $31.5(0.9)$ & 0.3 \\
\hline $\mathrm{F} 2$ & $31.2(0.8)$ & $31.9(0.8)$ & $31.6(0.8)$ & $31.9(0.5)$ & $31.2(0.8)$ & $31.2(0.9)$ & 0.7 \\
\hline F3 & $30.9(0.9)$ & $31.4(0.9)$ & $31.3(0.8)$ & $31.8(0.5)$ & $30.9(0.8)$ & $30.8(0.8)$ & 0.7 \\
\hline F4 & $30.8(0.8)$ & $31.4(0.9)$ & $31.3(0.8)$ & $31.7(0.6)$ & $30.8(0.8)$ & $30.6(0.9)$ & 0.6 \\
\hline F5 & $30.4(0.8)$ & $30.8(0.9)$ & $31.0(0.8)$ & $31.4(0.5)$ & $30.4(0.8)$ & $30.4(0.8)$ & 0.6 \\
\hline Nose & $33.1(0.8)$ & $33.4(0.8)$ & $32.7(0.9)$ & $31.9(0.9)$ & $32.5(0.7)$ & $32.4(0.8)$ & 0.05 \\
\hline Glabella & $35.1(0.1)$ & $35.1(0.1)$ & $34.8(0.2)$ & $34.6(0.3)$ & $35.0(0.1)$ & $34.9(0.2)$ & 0.5 \\
\hline
\end{tabular}

Data are mean temperatures in ${ }^{\circ} \mathrm{C}(\mathrm{SEM})$

${ }^{a}$ The start values were measured within the first $15 \mathrm{~min}$ of the given level, whereas the end values were measured within the last $15 \mathrm{~min}$ of the given level

${ }^{\mathrm{b}}$ Differences between the measurements for each location were assessed by repeated measures ANOVA

F1, the first finger; F2, the second finger; F3, the third finger; F4, the fourth finger; F5, the fifth finger; Hypo, hypoglycaemia; Normo, normoglycaemia 


\section{Discussion}

This study demonstrates that high-resolution infrared thermography can detect changes in Ts during hypoglycaemia in patients with type 1 diabetes. The decreases in Ts were significantly greater in hypoglycaemia-aware patients and accompanied by higher hypoglycaemia symptom scores and larger counterregulatory hormonal responses as compared with hypoglycaemia-unaware patients. Thus infrared thermography provides new information about the hypoglycaemia awareness phenotypes in type 1 diabetes.

Thermography detects electromagnetic radiation. Each infrared energy level is assigned a colour which results in a two dimensional image [19]. The advantage of this technique is that it is fast and precise, with a high spatial and temporal resolution, without requiring any direct skin contact. Furthermore, the remote recording does not interfere with sweat evaporation that is a major driver of hypoglycaemic Ts responses. The approach has proven useful in assessing Ts changes associated with regional anaesthesia [20,21], and has been suggested in ruling out fractures and monitoring vascular malformations, haemangiomas, burns and wound infections [22, 23]. With the use of thermal images we are able to show changes in Ts in relation to a blood glucose level of 2.0-2.5 mmol/l. Two other studies did not demonstrate decrease in Ts in patients with type 1 diabetes [7, 8]. The studies used methods requiring direct skin contact to assess Ts such as surface thermocouples on the forehead, abdomen, calf, shin and foot [8], or a thermistor placed on the forearm [7]. These methods may interfere with sweat evaporation at the detection site and may thereby be less sensitive during hypoglycaemia. The question remains whether this discrepancy is due to a higher sensitivity of the infrared thermography camera, the areas of skin investigated, or impaired awareness status in the participants, which was not addressed in the two studies $[7,8]$.

The unaware group not only had the expected diminished hypoglycaemia symptoms and counterregulatory hormonal responses to hypoglycaemia but an attenuated Ts decrease as well. Our results are in contrast to a study by Howorka et al [11] who reported a Ts response during hypoglycaemia but did not detect any difference in Ts between aware and unaware patients during hypoglycaemia. Again, there are distinctive methodological differences between the two studies. Howorka et al relied on methods requiring skin contact to assess Ts and they administered an intravenous bolus injection of insulin which lowered the glucose level to $2.0 \mathrm{mmol} / \mathrm{l}$ in the aware group and $1.6 \mathrm{mmol} / \mathrm{l}$ in the unaware group. Thereby the glucose level during hypoglycaemia was lower than that in our study and the difference in glucose level between the two groups was greater. This suggests that it might be necessary to study unaware patients at lower glucose levels to trigger a thermal response during hypoglycaemia similar to that of aware patients. This is in accordance with Gale et al [24] reporting that lower blood glucose levels produce larger thermoregulatory responses to hypoglycaemia when comparing glucose levels of 2.1, 1.8, 1.2 and $0.9 \mathrm{mmol} / \mathrm{l}$.

During hypoglycaemia, Ts changes differed among the nose, glabella and fingertips. Thus, Ts did not change significantly on the fingertips during hypoglycaemia. However, during recovery, Ts decreased on the fingertips, but only in the aware group. Our results are in accordance with a study from Wiles et al [25] demonstrating that finger blood flow remains high during hypoglycaemia in patients with type 1 diabetes despite a decrease in interdigital skin blood flow. It was only in the recovery period that the finger blood flow fell.

Evaporation of sweat is believed to be a main contributor to the temperature changes during hypoglycaemia [2]. During hypoglycaemia there is an increase in sympathetic skin responses similar to what can be found in patients with clinical hyperhidrosis [26]. This response is thought to be mediated by the central nervous system [26,27]. The differences in temperature response between aware and unaware patients might therefore be the results of differences within the central nervous system. This is in line with studies in rats showing that recurrent hypoglycaemia alters the glucose sensing in the ventromedial hypothalamus in the brain and blunts the counterregulatory response [28]. The thermography-assessed temperature response during hypoglycaemia might therefore be a novel modality in the characterisation of blunted sympatho-adrenal response leading to impaired hypoglycaemia awareness. The clinical implication of these findings is not yet certain and further investigations are necessary.

The strengths of this study are that the thermal recording set-up was standardised and performed at a stable room temperature making it possible to compare images throughout the study and also among participants. Furthermore, classification of the participants' awareness status fulfils the criteria of three internationally accepted classification methods for hypoglycaemia awareness [29]. The differences in symptom scores and counterregulatory responses further support the classification. Finally, participants wore a CGM in the days leading up to the study so that episodes with hypoglycaemia could be identified and the study postponed if necessary. This was done because antecedent hypoglycaemia could potentially blunt the symptomatic and hormonal responses to hypoglycaemia induced during the study [30].

The limitations to this study include the fact that the aware group was assessed at slightly higher glucose levels despite a lower glucose infusion rate during hypoglycaemia compared with the unaware group. The difficulty in reaching the same nadir glucose in both groups may be a consequence of better counterregulatory capacity of aware patients, which also could explain the lower glucose infusion rate during hypoglycaemia and recovery in this group. Even though the unaware group 
received a slightly stronger hypoglycaemic stimulus, their temperature response was smaller than in the aware group. Moreover, there were differences between the two groups at baseline. The aware group was younger with shorter duration of diabetes, which is to be expected since age and duration of disease are well-known risk markers for development of hypoglycaemia unawareness [31, 32]. After adjusting for this in the statistical analyses, the results still showed the hypoglycaemia-induced temperature response differed between the two groups, although there was only a trend on the nose during hypoglycaemia. Also, in this study we chose to analyse the forehead, nose and fingertips. These areas were chosen in part because they were compatible with the rest of the study set-up. There might be other areas where the hypoglycaemia-induced temperature changes are even more pronounced. In this study, no tests for neuropathies, other than beat-to-beat variation, were performed. Instead prevalence of neuropathy was based on questionnaires and the patient's medical records. It is therefore possible that the prevalence of neuropathy is higher. Both autonomous and peripheral neuropathy could potentially affect the thermoregulatory response. Further investigations are therefore needed to characterise the response in patients with neuropathy. Finally, the aim of this study was to analyse the response to hypoglycaemia in patients with type 1 diabetes, no nondiabetic control group was therefore included in this study and no euglycaemic control studies were performed. These aspects deserve attention in future studies.

In conclusion, Ts is decreased on the nose and forehead during hypoglycaemia in patients with type 1 diabetes as assessed by infrared thermography. The hypoglycaemiaassociated changes in Ts were more pronounced in patients with normal hypoglycaemia awareness compared with unaware patients.

Acknowledgements The authors would like to thank the participants and research nurses P. Banck-Petersen, T. Larsen and C. Hansen (Department of Cardiology, Nephrology and Endocrinology, Nordsjællands Hospital Hillerød, Denmark) for skilful technical assistance.

The results of this study were part of an abstract presented at the 50th annual EASD meeting, 15-19 September 2014, Vienna, Austria.

Funding This study was funded by research grants from the University of Southern Denmark, the Danish PhD School of Endocrinology, the Research Foundation at Nordsjællands Hospital, HypoSafe A/S, the Fog Foundation, the Augustinus Foundation, the Tvergaard Foundation, the Olga Bryde Nielsen Foundation and the Helen Rudes Foundation.

Duality of interest statement The authors declare that there is no duality of interest associated with this manuscript.

Contribution statement A-SS contributed to the conceptual design, recruited participants, conducted the study, researched the data, performed the data analysis and drafted the manuscript. UP-B, KHWL, CBJ, TWK and BT contributed to the conceptual design, data analysis and drafted the manuscript. SSD, CSF and LT contributed to the acquisition of data. JF, JJH, $\mathrm{BH}$ and $\mathrm{LH}$ contributed to data analysis. All authors have contributed significantly to the drafting, reviewing and editing of the manuscript and all authors approved the final version of the manuscript. A-SS is the guarantor of this work and, as such, had full access to all the data in the study and takes responsibility for the integrity of the data and the accuracy of the data analysis.

\section{References}

1. Gale EAM, Bennett T, Green JH, MacDonald IA (1981) Hypoglycaemia, hypothermia and shivering in man. Clin Sci (Lond) 61:463-469

2. Maggs DG, Scott AR, MacDonald IA (1994) Thermoregulatory responses to hyperinsulinemic hypoglycemia and euglycemia in humans. Am J Physiol 267:R1266-R1272

3. Shields SA, MacDowell KA, Fairchild SB, Campbell ML (1987) Is mediation of sweating cholinergic, adrenergic, or both? A comment on the literature. Psychophysiology 24:312-319

4. Harker M (2013) Psychological sweating: a systematic review focused on aetiology and cutaneous response. Skin Pharmacol Physiol 26:92-100

5. Alpert JS, Coffman JD (1969) Effect of intravenous epinephrine on skeletal muscle, skin, and subcutaneous blood flow. Am J Physiol 216:156-160

6. Molnar GW, Read RC (1974) Hypoglycemia and body temperature. JAMA 227:916-921

7. Aman J, Berne C, Ewald U, Tuvemo T (1990) Lack of cutaneous hyperemia in response to insulin-induced hypoglycemia in IDDM. Diabetes Care 13:1029-1033

8. Maggs DG, Macdonald IA, Tattersall RB (1994) Thermoregulatory responses to hyperinsulinaemic hypoglycaemia and euglycaemia in IDDM. Diabetologia 37:689-696

9. Cryer PE (2013) Mechanisms of hypoglycemia-associated autonomic failure in diabetes. NEJM 369:362-372

10. Cryer PE (2010) Hypoglycemia in type 1 diabetes mellitus. Endocrinol Metab Clin North Am 39:641-654

11. Howorka K, Heger G, Schabmann A, Skrabal F, Pumprla J (1998) Weak relationship between symptom perception and objective hypoglycaemia-induced changes of autonomic function in hypoglycaemia unawareness in diabetes. Acta Diabetol 35:1-8

12. Asghar S, Bjerregaard LS, Lundstrøm LH, Lund J, Jenstrup MT, Lange KHW (2014) Distal infrared thermography and skin temperature after ultrasound-guided interscalene brachial plexus block: a prospective observational study. Eur J Anaesthesiol 31:626-634

13. Sejling AS, Kjær TW, Pedersen-Bjergaard U et al (2015) Hypoglycemia-associated changes in the electroencephalogram in patients with type 1 diabetes and normal hypoglycemia awareness or unawareness. Diabetes 64:1760-1769

14. Pedersen-Bjergaard U, Pramming S, Thorsteinsson B (2003) Recall of severe hypoglycaemia and self-estimated state of awareness in type 1 diabetes. Diabetes Metab Res Rev 19:232-240

15. Gold AE, MacLeod KM, Frier BM (1994) Frequency of severe hypoglycemia in patients with type 1 diabetes and impaired awareness of hypoglycemia. Diabetes Care 17:697-703

16. Clarke WL, Cox DJ, Gonder-Frederick LA, Julian D, Schlundt D, Polonsky W (1995) Reduced awareness of hypoglycemia in adults with IDDM: a prospective study of hypoglycemic frequency and associated symptoms. Diabetes Care 18:517-522

17. Hepburn DA, Deary IJ, Frier BM, Patrick AW, Quinn JD, Fisher BM (1991) Symptoms of acute insulin-induced hypoglycemia in humans with and without IDDM. Factor-analysis approach. Diabetes Care 14:949-957 
18. McCrimmon RJ, Deary IJ, Gold AE et al (2003) Symptoms reported during experimental hypoglycaemia: effect of method of induction of hypoglyceamia and of diabetes per se. Diabet Med 20:507-509

19. Usamentiaga R, Venegas P, Guerediaga J, Vega L, Molleda J, Bulnes FG (2014) Infrared thermography for temperature measurement and non-destructive testing. Sensors (Basel) 14:12305-12348

20. Lange KHW, Jansen T, Asghar S, Kristensen PL, Skjønnemand M, Nørgaard P (2011) Skin temperature measured by infrared thermography after specific ultrasound-guided blocking of the musculocutaneous, radial, ulnar, and median nerves in the upper extremity. Br J Anaesth 106:887-895

21. Asghar S, Lundstrøm LH, Bjerregaard LS, Lange KHW (2014) Ultrasound-guided lateral infraclavicular block evaluated by infrared thermography and distal skin temperature. Acta Anaesthesiol Scand 58:867-874

22. Sanchis-Sánchez E, Salvador-Palmer R, Codoñer-Franch $P$ et al (2015) Infrared thermography is useful for ruling out fractures in paediatric emergencies. Eur J Pediatr 174:493-499

23. Saxena AK, Willital GH (2008) Infrared thermography: experience from a decade of pediatric imaging. Eur J Pediatr 167:757-764

24. Gale EAM, Bennett T, Macdonald IA, Holst JJ, Matthews JA (1983) The physiological effects of insulin-induced hypoglycaemia in man: responses at differing levels of blood glucose. Clin Sci (Lond) 65:263-271

25. Wiles PG, Grant PJ, Stickland MH, Dean HG, Wales JK, Davies JA (1988) Regional variation in skin blood flow response to hypoglycaemia in type 1 (insulin-dependent) diabetic patients without complications. Diabetologia 31:98-102

26. Koivikko ML, Airaksinen KE, Perkiömäki JS, Huikuri HV, Tapanainen JS, Kallio MA (2015) Effect of controlled hypoglycaemia on sympathetic skin response in patients with type 1 diabetes and control subjects. Diabet Med 32:556-560

27. Tugnoli V, Eleopra R, de Grandis D (1999) Hyperhidrosis and sympathetic skin response in chronic alcoholic patients. Clin Auton Res 9:17-22

28. Chan O, Sherwin O (2013) Influence of VMH fuel sensing on hypoglycemic response. Trends Endocrinol Metab 24:616-624

29. Høi-Hansen T, Pedersen-Bjergaard U, Thorsteinsson B (2010) Classification of hypoglycemia awareness in people with type 1 diabetes in clinical practice. J Diabet Complicat 24:392-397

30. Heller SR, Cryer PE (1991) Reduced neuroendocrine and symptomatic responses to subsequent hypoglycemia after 1 episode of hypoglycemia in nondiabetic humans. Diabetes 40:223-226

31. Pedersen-Bjergaard U, Pramming S, Heller SR et al (2004) Severe hypoglycaemia in 1076 adult patients with type 1 diabetes: influence of risk markers and selection. Diabetes Metab Res Rev 20: 479-486

32. Olsen SE, Asvold BO, Frier BM, Aune SE, Hansen LI, Bjørgaas MR (2014) Hypoglycaemia symptoms and impaired awareness of hypoglycaemia in adults with type 1 diabetes: the association with diabetes duration. Diabet Med 31:1210-1217 